\title{
Pelatihan dan Pembimbingan Penelitian Tindakan Kelas (PTK) pada Guru TK Se-Kabupaten Dharmasraya
}

\author{
Rahmatul Hayati*, Dwi Novri Asmara, Suci Rahma Putri \\ Universitas Dharmas Indonesia, \\ rahmatulwahyu341@gmail.com
}

\begin{abstract}
Abstrak
Berdasarkan studi awal yang dilakukan kepada guru TK Se-Kabupaten Dharmasraya, diperoleh hasil bahwa masih rendahnya kemampuan guru TK melakukan Penelitian Tindakan Kelas (PTK) dan penulisan laporan penelitiannya. Untuk itu perlu dilakukan pelatihan penelitian tindakan kelas, agar guru-guru mampu memperbaiki permasalahan-permasalahan yang ditemui di kelasnya sendiri. Tujuannya adalah agar guru semakin paham dan mampu melakukan PTK dan membuat laporan PTK secara sistematis dan terstruktur agar permasalahan yang ditemui dalam pembelajaran dapat diperbaiki. Kegiatan ini dilakukan di TK Aisyiyah Padang Bintungan yang dihadiri oleh 16 orang guru TK yang tersebar di Kabupaten Dharmasraya. Kegiatan ini berlangsung selama empat bulan dari Oktober 2019 hingga Januari 2020. Hasil kegiatan ini adalah meningkatnya kemampuan guru TK dalam melakukan dan membuat PTK. Dari kegiatan ini, masing-masing guru TK menghasilkan laporan PTK yang selanjutnya diseminarkan untuk kenaikan pangkat guru TK tersebut.
\end{abstract}

Kata Kunci: penelitian tindakan kelas, pelatihan, pembimbingan

\section{Classroom Action Research (CAR) Training and Guidance for Kindergarten Teachers in Dharmasraya Regency}

\begin{abstract}
Based on a preliminary study conducted on kindergarten teachers in Dharmasraya, it was found that the kindergarten teachers' ability to conduct a research through Classroom Action Research (CAR) and writing research reports were still low. Therefore, it is necessary to carry out a classroom action research trainin thus teachers are be able to fix the problems found in their own classes. The aim of this activity is to make teachers better understand and be able to carry out CAR and make a systematic and structured CAR report so that the problems encountered in learning can be corrected and solved. This activity was carried out at Aisyiyah Padang Bintungan Kindergarten, which was attended by 16 Kindergarten teachers in Dharmasraya. This activity was done for four months from October 2019 to January 2020. The result of this activity shows that kindergarten teachers can improve thier ability in conducting and making a reserach through CAR. Then, each kindergarten teacher does a research and produces CAR report which is then seminar on their promotion to high level of kindergarten teachers.
\end{abstract}

Keywords: classroom action reserach, training, guiding

\section{PENDAHULUAN}

Berdasarkan pada kebutuhan guru TK Kabupaten Dharmasraya dan terwadahinya bentuk kerja sama antara Lembaga Penelitian dan Pengabdian Kepada Masyarakat (LPPM) Universitas Dharmas Indonesia dengan Ikatan Guru Taman Kanak-kanak Indonesia (IGTKI) Kabupaten Dharmasraya ini, maka kegiatan pengabdian pada masyarakat dalam bentuk pelatihan penulisan karya ilmiah bagi guru TK Kabupaten Dharmasraya akan terus berlanjut pada tahun berikutnya. Selain itu, mengingat sangat penting diberlakukannya Peraturan Menteri Pendayagunaan Aparatur Negara Reformasi Birokrasi (Permenpan-RB) Nomor 16 Tahun 2009, bahwa seorang guru dituntut untuk membuat penulisan karya ilmiah khususnya penelitian tindakan kelas (PTK), di mana permenpan tersebut berguna 
untuk menyeimbangkan antara karier dan profesionalitas guru, maka seorang guru harus dapat membuat karya tulis ilmiah secara baik dan benar. Dengan penelitian tindakan kelas (PTK), guru juga dapat meneliti di kelasnya sendiri dengan tujuan memperbaiki kualitas pembelajaran melalui penelitian tindakan kelas (PTK).

Oleh karena itu, perlu dilakukan pelatihan penulisan karya ilmiah bagi guru Taman Kanak-kanak Kabupaten Dharmasraya agar dapat memberikan pemahaman lebih terhadap guru supaya dapat berpikir secara logis dan ilmiah dalam menguraikan dan membahas suatu permasalahan, serta dapat menuangkannya secara sistematis dan terstruktur. Selain itu, dalam penulisan karya ilmiah khususnya penulisan tindakan kelas (PTK) sesungguhnya merupakan hasil kreatif dari pengamatan sehari-hari seorang guru terhadap apa yang dialaminya, yang disusun secara komprehensif berdasarkan data akurat, dianalisis secara runtut, dan diakhiri dengan kesimpulan yang relevan (Afandi, 2014; Mulia \& Suwarno, 2016; Robson, 2016). Tentunya hal ini berhubungan dengan profesinya untuk menghasilkan kualitas pembelajaran yang lebih baik, sehingga mencapai hasil belajar yang optimal. PTK juga dilakukan agar dapat meningkatkan karier guru (Somatanaya \& Herawati, 2017). Atas dasar inilah, maka perlu diadakan lagi kegiatan pelatihan untuk meningkatkan profesionalisme guru melalui pelatihan penulisan PTK secara simultan dan berkesinambungan, sehingga dapat meningkatkan kualitas pembelajarannya di kelas.

\section{METODE PELAKSANAAN}

Untuk mencapai tujuan dan target yang diharapkan, maka kegiatan yang dilaksanakan adalah berupa pelatihan dan pembimbingan PTK dan laporan PTK. Pelatihan diberikan oleh pelaksana PkM yang terdiri dari lima orang Dosen FKIP Universitas Dharmas Indonesia kepada guru-guru TK yang tersebar di Kabupaten Dharmasraya. Guru yang dilatih dan dibimbing sebanyak 16 orang. Tempat kegiatan adalah di TK Aisyiyah Padang Bintungan Kabupaten Dharmasraya Provinsi Sumatera Barat. Pelatihan dilakukan selama empat bulan, yaitu dari 3 Oktober 2019 hingga 2 Januari 2020. 
Vol. 1, No. 3, November 2020

pp. 174-179 e-ISSN:

2722-2004

Title

Classroom Action Research (CAR) Training and Guidance for Kindergarten

Teachers in

Dharmasraya Regency

Author

R. Hayati,

D. N. Asmara, S. R. Putri

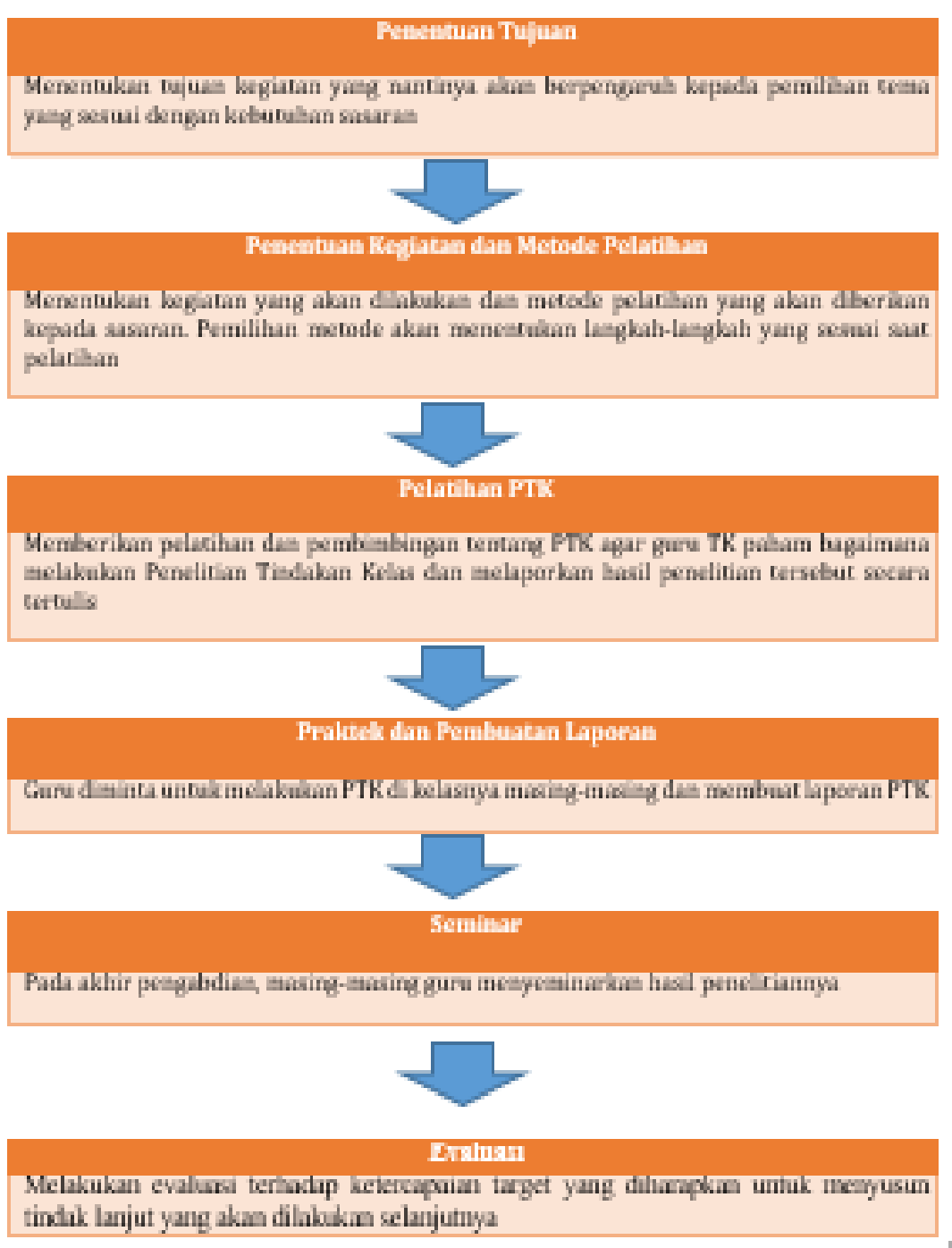

Gambar 1. Tahapan kegiatan pelatihan dan pembimbingan

Persiapan kegiatan, meliputi kegiatan koordinasi dengan dinas pendidikan Kabupaten Dharmasraya untuk mengurus perizinan dan survei tempat ke TK Aisyiyah Padang Bintungan; persiapan alat dan bahan, serta akomodasi.

Kegiatan pelatihan dan pembimbingan, meliputi pelatihan dan pembimbingan yang diberikan kepada guru TK Se-Kabupaten Dharmasraya tentang langkah-langkah dalam melakukan PTK dan tata cara pembuatan laporan PTK yang merupakan salah satu syarat kenaikan pangkat guru-guru.

Pada sesi penutupan, kegiatan meliputi evaluasi yang dilakukan kepada peserta, sehingga diketahui apa-apa saja kendala yang dihadapi, sehingga dapat dijadikan sebagai bahan perbaikan untuk kegiatan selanjutnya 
KANGMAS: Karya Ilmiah Pengabdian Masyarakat, 1 (3), November 2020 - 177 http://journal.neolectura.com/index.php/Kangmas

\section{HASIL DAN PEMBAHASAN}

Kegiatan ini merupakan kerja sama antara dinas pendidikan kabupaten Dharmasraya dengan Fakultas Keguruan dan Ilmu Pendidikan (FKIP) Universitas Dharmas Indonesia (Undhari), serta IGTKI se-Kabupaten Dharmasraya. Kegiatan ini diikuti oleh 16 orang guru TK yang tersebar di Kabupaten Dharmasraya yang merupakan perwakilan dari TK yang ada di Kabupaten Dharmasraya.

Sebelum dilaksanakan kegiatan ini, pengabdi terlebih dahulu melakukan survei awal kepada guru TK se-Kabupaten Dharmasraya tentang pemahamannya terhadap PTK. Dari survei awal yang telah dilakukan diperoleh hasil bahwa masih rendahnya pemahaman guru dalam pelaksanaan dan pembuatan laporan PTK. Berdasarkan hasil wawancara dengan guru-guru dan pihak dinas pendidikan Kabupaten Dharmasraya dapat disimpulkan bahwa masih rendahnya keinginan guru dalam melaksanakan PTK di kelasnya sendiri. Hal ini juga dibuktikan dengan masih banyaknya guru yang belum menyiapkan laporan PTK yang merupakan salah satu syarat kenaikan pangkat, serta sangat sedikitnya partisipasi guru-guru, baik TK, SD, SMP, maupun SMA Sederajat dalam mengikuti kegiatan lomba PTK Se-Kabupaten Dharmasraya. Berdasarkan studi awal tersebut, maka perlu dilakukan pelatihan dan pembimbingan PTK terhadap guru-guru, khususnya guru TK Se-Kabupaten Dharmasraya.

Pada awal kegiatan, pengabdi terlebih dahulu memberikan penjelasan secara umum tentang PTK. Hal ini bertujuan agar guru memahami pentingnya pelaksanaan PTK d kelasnya masing-masing. Dari kegiatan awal ini, guru sangat antusias sekali. Hal ini terlihat dari pertanyaan-pertanyaan yang diajukan guru seputar PTK. Dari pertanyaan yang diajukan guru, sangat terlihat bahwa masih rendahnya pemahaman guru dalam pelaksanaan PTK ini.

Setelah dijelaskan tentang PTK, masing-masing guru diminta untuk melaksanakan PTK dengan terlebih dahulu melakukan bimbingan kepada masingmasing pembimbing yang telah dibagi. Awalnya guru diminta untuk membuat proposal penelitian dan guru diminta untuk melakukan penelitian setelah proposal tersebut disetujui oleh masing-masing pembimbing. Pengabdian ini dilakukan $1 \mathrm{kali}$ dalam seminggu. Gambar 1 merupakan kegiatan bimbingan yang dilakukan pengabdi kepada guru.
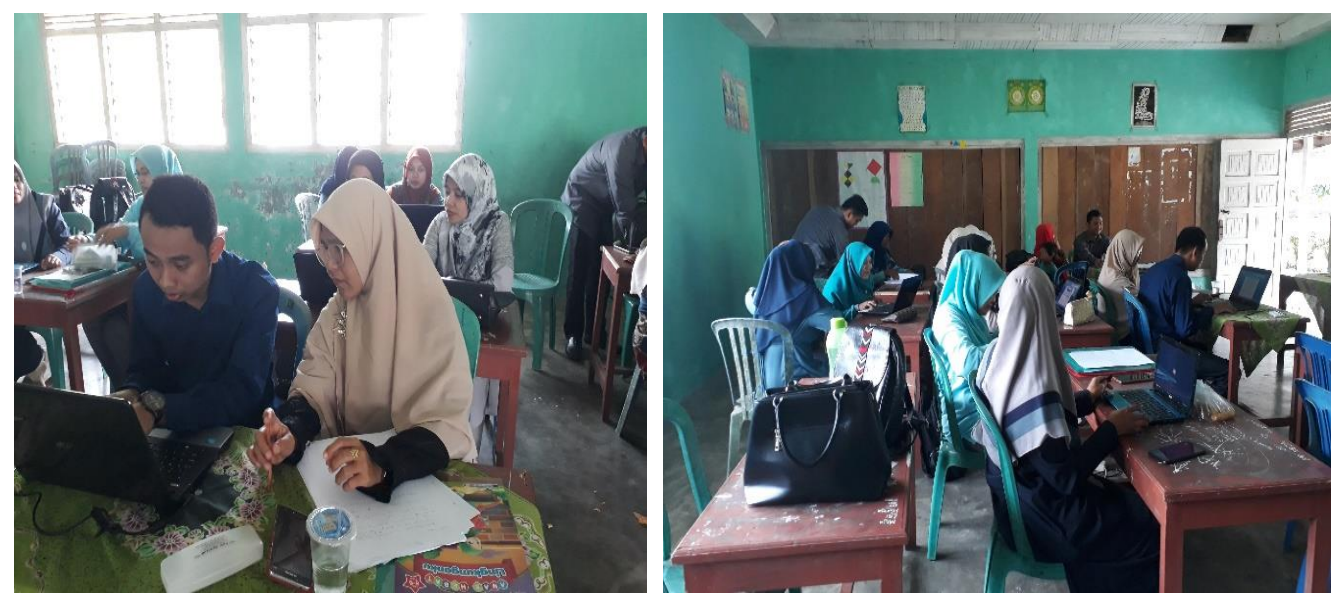

Gambar 2. Kegiatan bimbingan pelaksanaan PTK dan pembuatan laporan 
Vol. 1, No. 3,

November

2020

pp. 174-179

e-ISSN:

2722-2004

Title

Classroom

Action Research

(CAR) Training

and Guidance

for Kindergarten

Teachers in

Dharmasraya

Regency

Author

R. Hayati,

D. N. Asmara,

S. R. Putri

Kegiatan pembimbingan ini sangat penting dilaksanakan karena berdasarkan hasil pembimbingan yang dilakukan, masih banyak guru-guru yang belum paham dengan PTK dan pembuatan laporan PTK, sedangkan PTK ini sangat penting dilakukan oleh guru karena melalui PTK, guru dapat memperbaiki permasalahanpermasalahan dalam pembelajaran yang ditemuinya di kelasnya sendiri (Igak Wardani \& Kuswaya Wihardit, 2009).

Untuk meningkatkan pemahaman guru dalam pelaksanaan PTK dan pembuatan laporan PTK, dosen Universitas Dharmas Indonesia (pengabdi) melakukan bimbingan secara individu kepada guru. Pembimbingan ini tidak hanya dilakukan saat pertemuan saja, namun guru bisa melakukan bimbingan di luar pertemuan. Hal ini bertujuan agar guru cepat dalam memahami PTK ini dan menyelesaikan PTK sesuai dengan waktu yang telah ditentukan. Setelah selesai pembuatan proposal dan sudah disetujui pembimbing, guru diminta untuk melakukan penelitian minimal empat kali pertemuan. Setelah selesai penelitian, masing-masing guru diminta membuat laporan hasil penelitian dengan dibimbing oleh masing-masing pembimbing.

Pada tahapan akhir, setelah selesai pembuatan laporan, hasil penelitian diseminarkan oleh masing-masing guru dengan diikuti oleh pihak dinas pendidikan Kabupaten Dharmasraya, pembimbing, dan penguji. Hasil akhirnya dapat dijadikan sebagai salah satu persyaratan untuk pengajuan kenaikan pangkat. Gambar 3 merupakan kegiatan seminar yang dilakukan oleh guru TK yang telah melakukan pelatihan dan pembimbingan PTK dengan dihadiri oleh pihak dinas Kabupaten Dharmasraya.
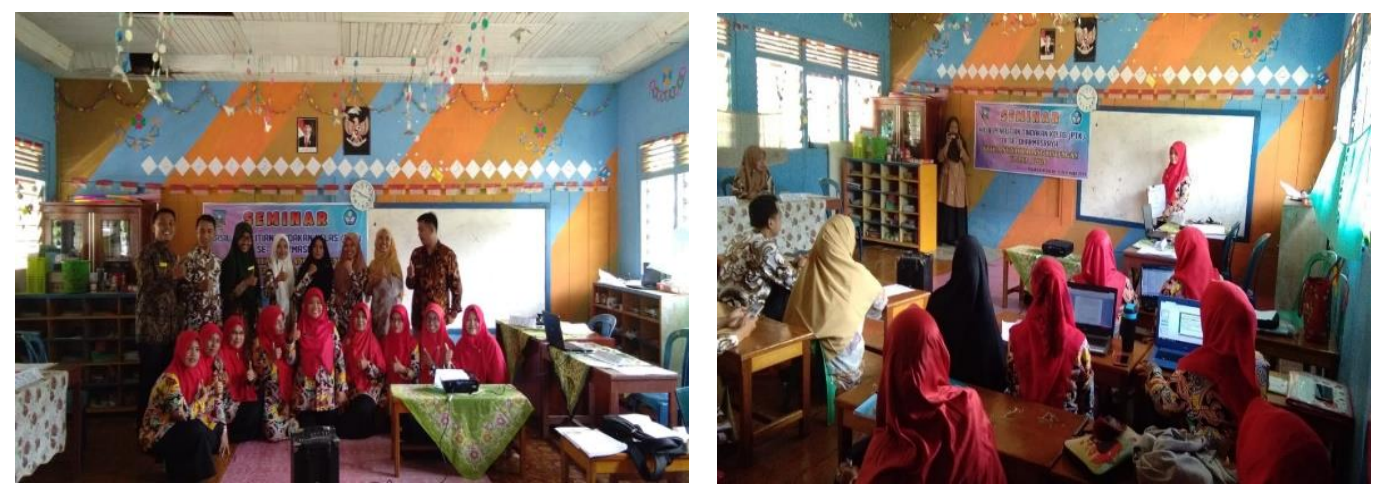

Gambar 3. Seminar hasil PTK

Dari Gambar 3 terlihat bahwa guru melaksanakan seminar hasil penelitiannya dengan dihadiri oleh pembimbing dan penguji. Kegiatan ini secara umum berjalan dengan lancar. Pelatihan dan pembimbingan PTK ini dimulai perdana dilakukan pada guru TK yang selanjutnya akan dilakukan ke sekolahsekolah di Kabupaten Dharmasraya yang membutuhkan pelatihan dan pembimbingan PTK.

Guru-guru TK yang mengikuti kegiatan ini memberikan apresiasi pada kegiatan ini, karena masih banyak guru, khususnya guru TK yang kurang paham langkah-langkah dalam melakukan PTK dan membuat laporan PTK yang merupakan salah satu syarat untuk kenaikan pangkat guru-guru. PTK ini sangat penting dilakukan oleh guru karena hakikat PTK adalah suatu bentuk penelitian refleksi diri yang dilakukan oleh guru dan hasilnya dapat dijadikan sebagai upaya 
untuk memecahkan permasalahan yang ada (Robson, 2016; Kusuma dan Dwitagama, 2010).

Berdasarkan hasil pelatihan dan pembimbingan PTK yang dilakukan, maka sangat perlu kiranya dilakukan pelatihan dan pembimbingan ini secara berkelanjutan agar dapat meningkatkan profesionalisme guru, karena guru yang profesional perlu melihat dan menilai sendiri secara kritis tentang pembelajarannya di kelas (Suyanto, 1997). Melalui PTK seorang guru dapat memperbaiki pembelajaran yang dikelolanya karena sasaran akhir PTK adalah untuk perbaikan pembelajaran (Wardani \& Wihardit, 2009)

\section{SIMPULAN}

Program pelatihan dan pembimbingan PTK dapat diselenggarakan dengan baik dan berjalan dengan lancar sesuai dengan rencana kegiatan yang telah disusun meskipun belum semua peserta pelatihan menguasai dengan baik materi yang disampaikan. Kegiatan ini mendapat sambutan sangat baik, baik oleh guru maupun dinas pendidikan Kabupaten Dharmasraya. Walaupun kenyataannya tidak semua guru TK yang ada di lingkup Kabupaten Dharmasraya bisa hadir, tetapi setidaknya sudah mewakili gugus tugas masing-masing Kecamatan di Kabupaten Dharmasraya. Luaran dari pengabdian ini adalah berupa laporan PTK yang telah diseminarkan sesuai dengan target pengabdian ini.

\section{DAFTAR PUSTAKA}

Afandi, M. (2014). Pentingnya Penelitian Tindakan Kelas Bagi Guru dalam Pembelajaran di Sekolah Dasar. 1(1).

Wardani, I. \& Wihardit, K. (2009). Penelitian Tindakan Kelas. Jakarta: Universitas Terbuka.

Mulia, D. S., \& Suwarno. (2016). PTK (Penelitian Tindakan Kelas) Dengan Pembelajaran Berbasis Kearifan Lokal dan Penulisan Artikel Ilmiah di SD Negeri Kalisube, Banyumas. Khazanah Pendidikan Jurnal Ilmiah Kependidikan, Vol. IX, No. 2. Retrieved from

http://jurnalnasional.ump.ac.id/index.php/khazanah/article/view/1062/983

Robson, M. (2016). Action research: principles and practice. In Action Learning: Research and Practice (Vol. 13).

https://doi.org/10.1080/14767333.2016.1220174

Somatanaya, A. A. G., \& Herawati, L. (2017). Pelatihan Penelitian Tindakan Kelas (PTK) Bagi Peningkatan Karier Guru-guru Sekolah Dasar Kota Tasikmalaya. 3(1), 169-175.

Suyanto. (1997). Mahir Melakukan Penelitian Tindakan Kelas. Bandung: Yapinda Press. 